\title{
A DIALLEL CROSS OF GENOTYPES AND GENOTROPHS OF LINUM
}

\author{
A. DURRANT and H. TYSON* \\ Department of Agricultural Botany, University College of Wales, Aberystwyth
}

Received 8.xi.63

\section{INTRODUCTION}

Heritable changes are induced in flax plants of the variety Stormont Cirrus when they are supplied with different fertilisers and grown for at least the first 5 weeks in a heated greenhouse (Durrant, I962a). The original variety is changed into a large stable genotroph $(\mathrm{L})$ when nitrogen, phosphorus and potassium are applied with suitable soil conditions, and into a small stable genotroph $(\mathbf{S})$ when nitrogen and potassium are applied. L may be up to six times the weight of $\mathrm{S}$ depending upon the environment in which they are grown and both have remained unchanged in inheritance for eight generations irrespective of fertilisers subsequently supplied, although possibly temporary changes may occur at certain day/night temperature combinations.

Both $\mathrm{L}$ and $\mathrm{S}$ behave as two distinct genetic types in giving equilinear inheritance when they are reciprocally crossed and no transmission through their reciprocal grafts. On the other hand, unlike orthodox genetic types, the variation in the $F_{1}$ and the $F_{2}$ of the $S \times L$ cross is always greater than in the $\mathbf{L} \times \mathbf{S}$ cross, and both are greater than the variation in the parents (Durrant, $1962 b$ ). The weights of individual $F_{1}$ plants are positively correlated with their mean family weights in the $F_{2}$ and it is supposed that there is an immediate release of variation in the $F_{1}$ with the production of a number of heritable forms (epitrophs).

A diallel cross was made in 1957 with the two genotrophs, L and S, two other flax varieties and two linseed varieties to determine whether the two genotrophs behaved on crossing in any exceptionally different way from the genotypes. The genotrophs had been induced from the same variety of flax and should presumably have certain features in common. A study of their dominance relations, interactions, variation and nuclear/cytoplasmic interactions should give information on how far they are genetically alike, and how far they are genetically different from the genotypes.

\section{THE PARENTAL GENERATION}

The two genotrophs and the four genotypes will be referred to collectively as genos. Plants of the two genotrophs used for the crosses were the second generation of plants which received the original inducing treatments, the first generation having been grown in a

* Now at the Canada Department of Agriculture Experimental Farm, Morden, Manitoba, Canada. 
uniform environment with nitrogen, phosphorus and potassium. The two flax varieties were Percello $(\mathrm{P})$ and Mandarin $(\mathrm{M})$, and the two linseed varieties Dakota (D) and Royal (R).

The year previous to their use as parents in the diallel cross the four genotypes were grown for the first few weeks in a cool greenhouse with J.I. base fertiliser and transplanted into the field with a compound fertiliser. No rigorous tests were made on these plants to determine whether any inherited changes had been induced in them by these conditions, but they are unlikely to have occurred because of the cooler conditions and no excess of any nutrient. The chromosomes of all six genos were checked and each had a full complement of thirty without any cytological abnormalities.

In 1957 the plants used for crossing were germinated in a warm greenhouse, grown for 3 weeks in a cool greenhouse and transplanted into the field where they were set out in three replicates each containing twenty plants of each geno. Two-thirds of the plants survived the subsequent drought and wind damage. Crosses were made between the genos and between plants of the same genos, and approximately equal amounts of the crossed seed from each of the three replicates were assigned to the two replicates of the $F_{1}$ of the diallel cross grown the following year.

\section{THE FIRST GENERATION}

The first generation had approximately the same environmental conditions as the parents. There were six plots of five plants of each of the thirty-six $F_{1}$ families; three plots of each $F_{1}$ family were randomised in one replicate, and three plots of each in a second replicate, both in boxes in the greenhouse and on transplanting into the field. Within a few weeks of transplanting there was an obvious sharp discontinuity in soil fertility which cut through the centre of both replicates. Since at least one of the three plots of each $F_{1}$ family was in each of the high and low fertility areas of each replication the measurements obtained in the low fertility area were adjusted by means of a regression of low fertility measurements on high fertility measurements. Each of the two replicates was adjusted separately from its own regression so that the interaction of the two replicates with the corrected plot totals of each $F_{1}$ family in each replicate provided a valid assessment of the error variation.

Plant weight, centre shoot weight and length, side shoot weight and length, flowering time and rooo gram seed weight of seed from the parents were measured, and analysed by the methods of diallel analysis of Jinks (1954) and Hayman (1954). Plant weight will be discussed in greatest detail here.

\section{(i) Plant weight}

The plant weights are given in table I and the regression of array covariances on array variances in fig. I shows that dominance is 
present without interaction. The correlation coefficient $(r)$ of $\mathrm{V} r+\mathrm{Wr}$ with the parental family weight is $-0.6 \mathrm{I}$, dominance acting mainly in a positive direction. Since the two genotrophs $(\mathrm{L}, \mathrm{S})$ lie close together they have practically the same amount of dominance which is intermediate with respect to the other varieties, and it would appear

TABLE I

Mean plant weights (g.), mean side-shoot weights and mean centre-shoot weights (in that order in each cell of the table) of $F_{1}$ families of diallel cross. The component weights do not sum exactly to the plant weights because each character was adjusted separately in allowing for soil heterogeneity (see text).

\begin{tabular}{|c|c|c|c|c|c|c|c|c|c|}
\hline & & & $P$ & $\mathbf{M}$ & $\mathbf{R}$ & D & $\mathbf{S}$ & $\mathrm{L}$ & Total \\
\hline$P$ & . & . & $\begin{array}{l}68 \\
15 \\
54\end{array}$ & $\begin{array}{l}59 \\
13 \\
47\end{array}$ & $\begin{array}{r}110 \\
35 \\
61\end{array}$ & $\begin{array}{l}89 \\
25 \\
62\end{array}$ & $\begin{array}{r}63 \\
7 \\
57\end{array}$ & $\begin{array}{l}80 \\
18 \\
62\end{array}$ & $\begin{array}{l}469 \\
113 \\
343\end{array}$ \\
\hline $\mathbf{M}$ & · & • & $\begin{array}{l}52 \\
13 \\
39\end{array}$ & $\begin{array}{r}31 \\
6 \\
26\end{array}$ & $\begin{array}{l}98 \\
27 \\
69\end{array}$ & $\begin{array}{l}79 \\
14 \\
57\end{array}$ & $\begin{array}{r}35 \\
6 \\
3^{0}\end{array}$ & $\begin{array}{l}39 \\
10 \\
31\end{array}$ & $\begin{array}{r}334 \\
76 \\
252\end{array}$ \\
\hline $\mathbf{R}$ & • & . & $\begin{array}{r}130 \\
37 \\
9^{1}\end{array}$ & $\begin{array}{r}114 \\
41 \\
88\end{array}$ & $\begin{array}{r}121 \\
42 \\
75\end{array}$ & $\begin{array}{r}16 \\
57 \\
89\end{array}$ & $\begin{array}{l}89 \\
17 \\
74\end{array}$ & $\begin{array}{r}105 \\
22 \\
76\end{array}$ & $\begin{array}{l}705 \\
216 \\
493\end{array}$ \\
\hline $\mathrm{D}$ & . & . & $\begin{array}{r}100 \\
42 \\
57\end{array}$ & $\begin{array}{l}69 \\
17 \\
52\end{array}$ & $\begin{array}{r}146 \\
54 \\
9^{1}\end{array}$ & $\begin{array}{l}91 \\
35 \\
56\end{array}$ & $\begin{array}{l}66 \\
17 \\
48\end{array}$ & $\begin{array}{l}97 \\
31 \\
64\end{array}$ & $\begin{array}{l}569 \\
196 \\
368\end{array}$ \\
\hline S & · & - & $\begin{array}{l}59 \\
14 \\
46\end{array}$ & $\begin{array}{r}25 \\
6 \\
22\end{array}$ & $\begin{array}{l}93 \\
18 \\
73\end{array}$ & $\begin{array}{l}67 \\
17 \\
52\end{array}$ & $\begin{array}{r}27 \\
6 \\
22\end{array}$ & $\begin{array}{l}54 \\
13 \\
3^{8}\end{array}$ & $\begin{array}{r}325 \\
74 \\
253\end{array}$ \\
\hline $\mathbf{L}$ & . & . & $\begin{array}{l}91 \\
23 \\
69\end{array}$ & $\begin{array}{l}41 \\
11 \\
3^{2}\end{array}$ & $\begin{array}{l}83 \\
26 \\
56\end{array}$ & $\begin{array}{r}120 \\
44 \\
75\end{array}$ & $\begin{array}{l}57 \\
12 \\
37\end{array}$ & $\begin{array}{l}61 \\
17 \\
56\end{array}$ & $\begin{array}{l}453 \\
133 \\
325\end{array}$ \\
\hline Tota & & . & $\begin{array}{l}500 \\
144 \\
356\end{array}$ & $\begin{array}{r}339 \\
94 \\
267\end{array}$ & $\begin{array}{l}651 \\
202 \\
425\end{array}$ & $\begin{array}{l}592 \\
192 \\
391\end{array}$ & $\begin{array}{r}337 \\
65 \\
268\end{array}$ & $\begin{array}{l}436 \\
111 \\
327\end{array}$ & $\begin{array}{r}2855 \\
808 \\
2034\end{array}$ \\
\hline
\end{tabular}

therefore that $\mathrm{L}$ and $\mathrm{S}$ differ only in additive genetic factors which, together with the lack of interaction between them or with other varieties indicates they retain, despite the overall difference in weight, intrinsically similar characteristics which are presumably those of the original variety from which they had been induced.

Inspection of table I shows that there is nevertheless a non-additive relationship between $L$ and $S$, for their $F_{1}$ has an average dominance value, or more strictly, potence ratio (Wigan, 1944), of o.68, expressed as the deviation from the midparent value divided by half the parental difference. Since there are large differences between the weights of the parental families, up to about 400 per cent., it is likely that a change of scale would be helpful in bringing out relations which are not evident in fig. $I$. Furthermore, in the $F_{2}$, to be described, there is a strong positive correlation between parent family means and 02 
variances so that for analytical purposes at least a transformation is desirable. Fig. 2 gives the regression of array covariances on array variances after the data had been transformed to logs. There is again

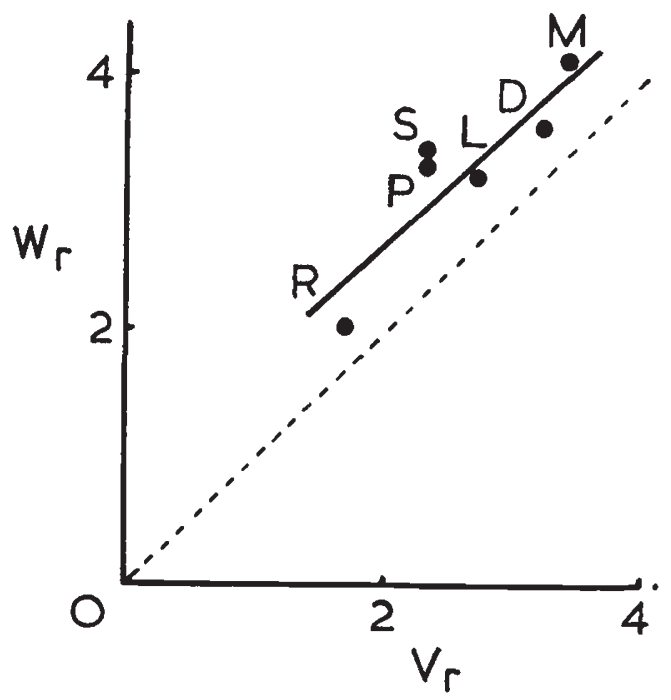

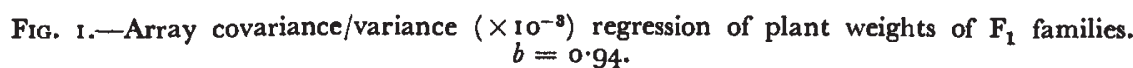

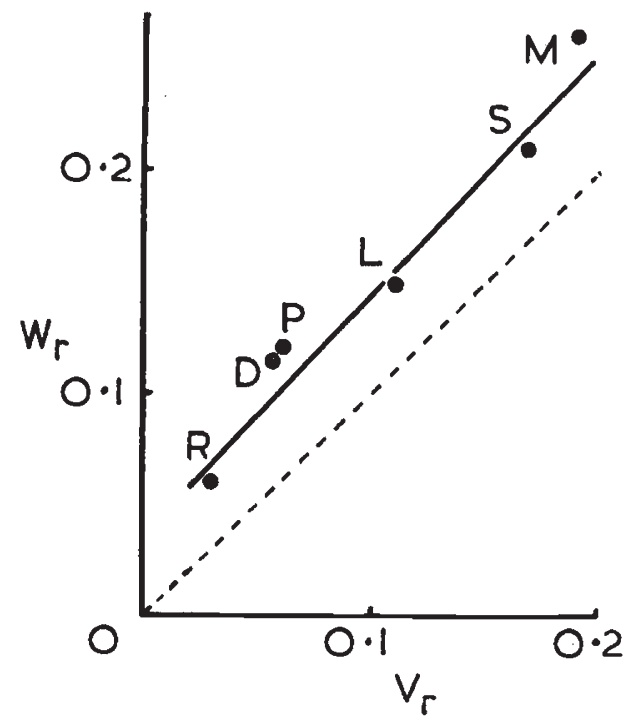

Fig. 2.-Array covariance/variance $\left(\times \mathrm{IO}^{3}\right)$ regression of log. plant weights of $F_{1}$ families. $b=\mathbf{I} \cdot 1$.

good evidence of dominance and no evidence of interaction. But the positions of the points have changed and in fact the correlation of $\mathrm{W} r+\mathrm{V} r$ with the parental family weights is now virtually complete with a value of -0.96 . That is, there is a strict relationship between the weights and dominance relations of the parents, dominance acting 
in a positive direction throughout so that large parents have more dominant alleles and small parents more recessive alleles.

Apart from their additive difference then the two genotrophs behave in a similar manner, and such dominance deviations that do occur fit into the pattern of dominance shown by the varieties in general. Table 2 gives the analysis of the transformed data using

TABLE 2

Analysis of variance of log. plant weights of $F_{1}$ families of diallel cross.

Mean squares $\times 10^{8}$

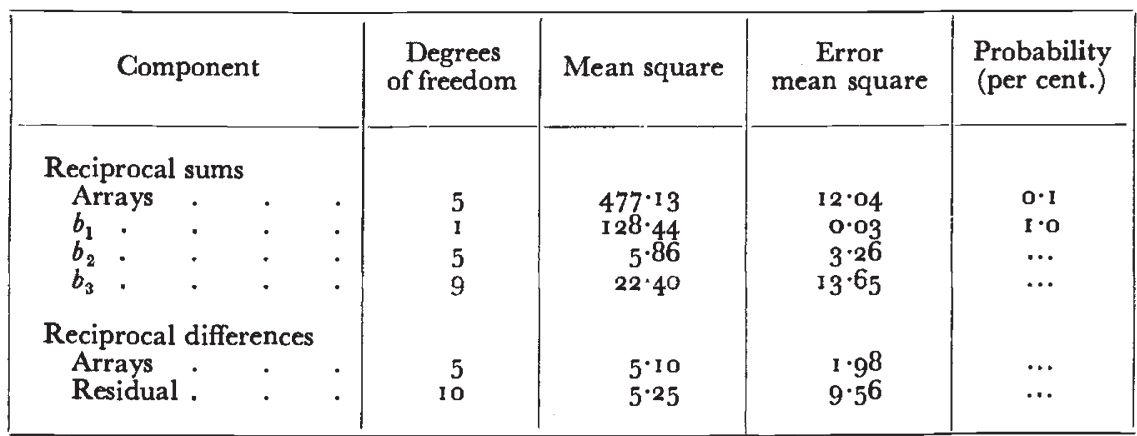

Hayman's (1954) analysis. Only the array's component and the average dominance component $\left(b_{1}\right)$ are significant. There are no significant differences among the reciprocals so that in this respect too the genotrophs are no different from the genotypes.

\section{(ii) Centre and side shoot weight}

Centre and side shoot weights are given in table I, and their array covariance/variance graphs in figs. 3 and 4 . In both cases the

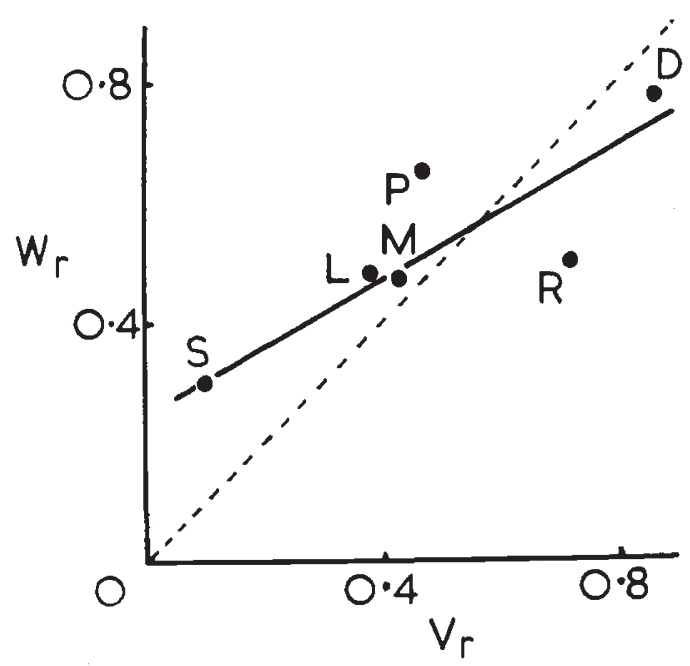

FIG. 3.-Array covariance/variance $\left(\times 10^{-3}\right)$ regression of side shoot weights of $F_{1}$ families. $b=0 \cdot 56$. 
genotrophs lie together on the regression line. Both regressions have a slope of less than one, suggesting interaction, particularly in the case of side shoot weight. Removing the arrays in turn and noting the

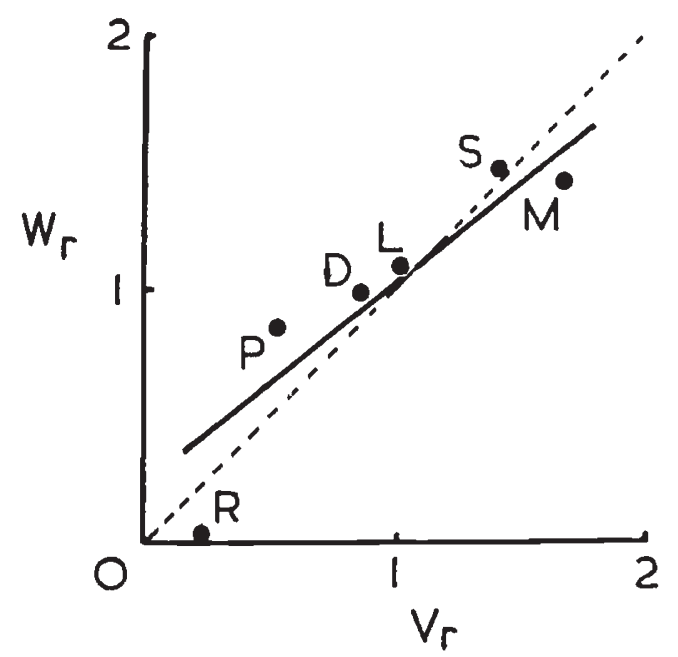

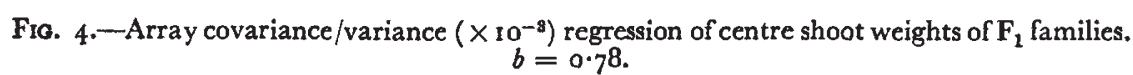

increase in slope (table 3 ) it would appear that Dakota, Royal and the large genotroph are chiefly concerned in the interaction in side shoot weight; and possibly Percello, Mandarin, Dakota and the large

TABLE 3

Covariance/variance regression coefficients after removal of different arrays

\begin{tabular}{|c|c|c|}
\hline \multirow{2}{*}{ Array removed } & \multicolumn{2}{|c|}{ Regression coefficient } \\
\cline { 2 - 3 } & $\begin{array}{c}\text { Side shoot } \\
\text { weight }\end{array}$ & $\begin{array}{c}\text { Centre shoot } \\
\text { weight }\end{array}$ \\
\cline { 2 - 3 } None & 0.56 & 0.78 \\
P & 0.58 & 0.94 \\
M & 0.58 & 0.91 \\
D & 0.65 & 0.77 \\
S & 0.85 & 0.89 \\
L & 0.47 & 0.76 \\
0.62 & 0.94 \\
\hline
\end{tabular}

genotroph in centre shoot weight. If so there is a difference here between the two genotrophs in that one is involved in the interactions and the other not.

There are no significant reciprocal differences and, overall, the genotrophs behave with regard to these two characters as they do with the untransformed plant weights, for they have a greater similarity 
in their dominance relations than the genotypes in general, but otherwise do not appear to be fundamentally different from them in their behaviour on crossing. Three other characters, centre shoot length, side shoot length and seed weight, gave the same type of result. The array covariance/variance graph showed no relation between the genotrophs in flowering time but here the differences between the parents were very small and there was no significant dominance component.

\section{ANALYSIS OF $F_{2}$ FAMILY MEANS}

Six replicates of the second generation were grown the following year, each of the thirty-six families in each replicate consisting of ten plants. The mean plant weights are given in table 4 and the array

TABLE 4

Mean plant weights, family variances of plant weights and family variances $\left(\times 10^{4}\right)$ of log. plant weights (in that order) of $F_{2}$ families of diallel cross

\begin{tabular}{|c|c|c|c|c|c|c|c|c|c|}
\hline & & & $\mathbf{P}$ & $\mathbf{M}$ & $\mathbf{R}$ & D & $S$ & L. & Total \\
\hline $\mathbf{P}$ & . & . & $\begin{array}{r}70 \\
347 \\
145\end{array}$ & $\begin{array}{r}54 \\
3^{89} \\
3^{0} 3\end{array}$ & $\begin{array}{r}108 \\
1114 \\
197\end{array}$ & $\begin{array}{r}88 \\
1073 \\
227\end{array}$ & $\begin{array}{r}70 \\
616 \\
290\end{array}$ & $\begin{array}{r}81 \\
539 \\
195\end{array}$ & $\begin{array}{r}471 \\
4078 \\
1357\end{array}$ \\
\hline $\mathbf{M}$ & . & - & $\begin{array}{r}57 \\
356 \\
193\end{array}$ & $\begin{array}{r}38 \\
84 \\
122\end{array}$ & $\begin{array}{r}75 \\
750 \\
272\end{array}$ & $\begin{array}{r}59 \\
543 \\
39^{2}\end{array}$ & $\begin{array}{r}4 I \\
266 \\
335\end{array}$ & $\begin{array}{r}58 \\
337 \\
183\end{array}$ & $\begin{array}{r}328 \\
2336 \\
1497\end{array}$ \\
\hline R & . & . & $\begin{array}{r}97 \\
1074 \\
24^{\circ}\end{array}$ & $\begin{array}{r}87 \\
890 \\
237\end{array}$ & $\begin{array}{r}107 \\
1143 \\
173\end{array}$ & $\begin{array}{l}105 \\
779 \\
\text { 1 } 36\end{array}$ & $\begin{array}{r}85 \\
933 \\
332\end{array}$ & $\begin{array}{l}\mathrm{IO}_{4} \\
884 \\
278\end{array}$ & $\begin{array}{r}585 \\
5703 \\
1396\end{array}$ \\
\hline D & . & . & $\begin{array}{r}77 \\
634 \\
208\end{array}$ & $\begin{array}{r}64 \\
542 \\
298\end{array}$ & $\begin{array}{r}112 \\
1179 \\
188\end{array}$ & $\begin{array}{r}87 \\
530 \\
178\end{array}$ & $\begin{array}{r}7^{\circ} \\
83^{\circ} \\
33^{\circ}\end{array}$ & $\begin{array}{r}83 \\
884 \\
280\end{array}$ & $\begin{array}{r}493 \\
4599 \\
1482\end{array}$ \\
\hline $\mathrm{S}$ & . & . & $\begin{array}{r}60 \\
442 \\
323\end{array}$ & $\begin{array}{r}47 \\
178 \\
167\end{array}$ & $\begin{array}{r}92 \\
1234 \\
260\end{array}$ & $\begin{array}{r}63 \\
646 \\
288\end{array}$ & $\begin{array}{r}3^{6} \\
199 \\
3^{\circ 05}\end{array}$ & $\begin{array}{r}59 \\
671 \\
3^{82}\end{array}$ & $\begin{array}{r}357 \\
3370 \\
1725\end{array}$ \\
\hline L & . & . & $\begin{array}{r}77 \\
634 \\
255\end{array}$ & $\begin{array}{r}57 \\
33^{6} \\
23^{8}\end{array}$ & $\begin{array}{r}103 \\
1494 \\
310\end{array}$ & $\begin{array}{r}92 \\
710 \\
223\end{array}$ & $\begin{array}{r}59 \\
357 \\
200\end{array}$ & $\begin{array}{r}73 \\
653 \\
253\end{array}$ & $\begin{array}{r}46 \mathrm{r} \\
4184 \\
1479\end{array}$ \\
\hline Total & & - & $\begin{array}{r}43^{8} \\
34^{87} \\
\text { I } 364\end{array}$ & $\begin{array}{r}347 \\
2419 \\
1365\end{array}$ & $\begin{array}{r}597 \\
6914 \\
1400\end{array}$ & $\begin{array}{r}494 \\
428 \mathrm{I} \\
\mathrm{I} 444\end{array}$ & $\begin{array}{r}361 \\
3201 \\
1792\end{array}$ & $\begin{array}{r}458 \\
3968 \\
1571\end{array}$ & $\begin{array}{r}2694 \\
24270 \\
893^{6}\end{array}$ \\
\hline
\end{tabular}

covariance/variance graph in fig. 5. As with the $F_{1}$ plant weights there is good evidence of dominance and no evidence of interaction. The correlation of $\mathrm{Wr}+\mathrm{Vr}$ with the parental family weights is also about the same $\left(r=-0.5^{8}\right)$ but the $\mathrm{F}_{1} / \mathrm{F}_{2}$ correlation of $(\mathrm{Wr}+\mathrm{Vr})$ is not particularly high $(r=0.53)$, so that the order of the points on the regression line are different to some extent in the two generations. The genotrophs, however, again lie together on the regression line. A log. transformation alters the points on the regression line (fig. 6) 


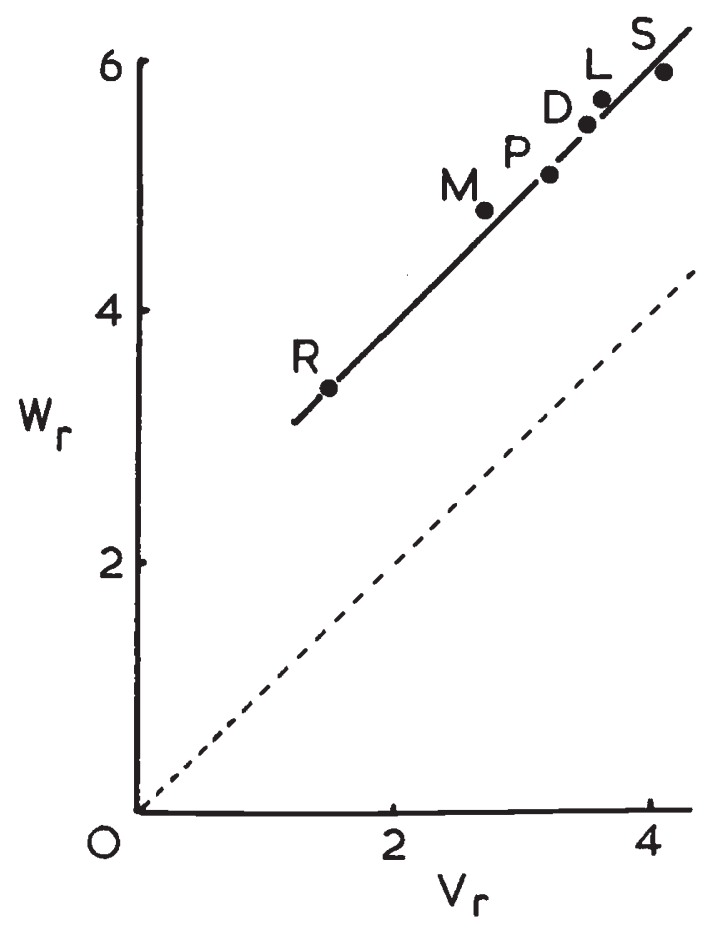

FIg. 5.-Array covariance/variance $\left(\begin{array}{c}\left(x_{10} \mathrm{O}^{-3}\right) \\ b=\mathrm{I}\end{array}\right.$ regression of plant weights of $\mathrm{F}_{\mathrm{a}}$ families.

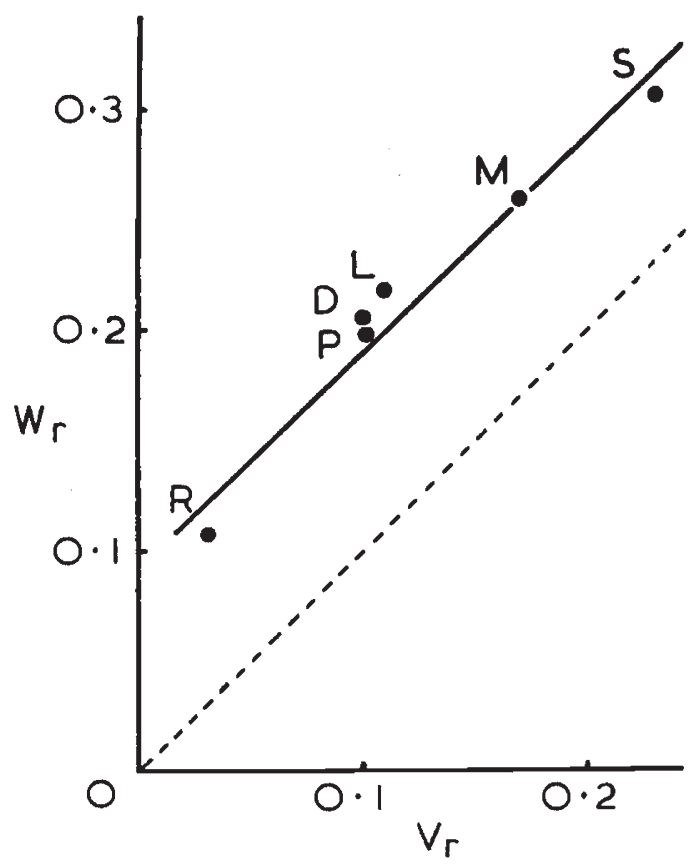

Fig. 6.-Array covariance/variance $\left(\underset{b}{\times 10^{3}}\right)$ regression of log. plant weights of $F_{2}$ families. 
in much the same way as in the $F_{1}$, for the correlation coefficient of $(\mathrm{Wr}+\mathrm{V} r) /$ parents now becomes - 0.94 , comparable with -0.96 in the $F_{1}$, and the $F_{1} / F_{2}$ correlation for $\mathrm{Wr}+\mathrm{Vr}$ rises to 0.89 .

On the log. scale therefore the $F_{1}$ and $F_{2}$ give very similar results. This is also shown by the analysis of variance of the transformed $F_{2}$ data (table 5), the components having relatively the same order of magnitude as in the $F_{1}$ (table 2). The $F_{1} / F_{2}$ correlation coefficients (table 5) for the arrays component is almost complete, and the $b_{2}$ and $b_{3}$ components, although not significant in the two analyses of variance

TABLE 5

Analysis of variance of log. plant weights of $F_{2}$ families of diallel cross, and $F_{1} / F_{2}$ correlation coefficients. Mean squares $\times 10^{8}$

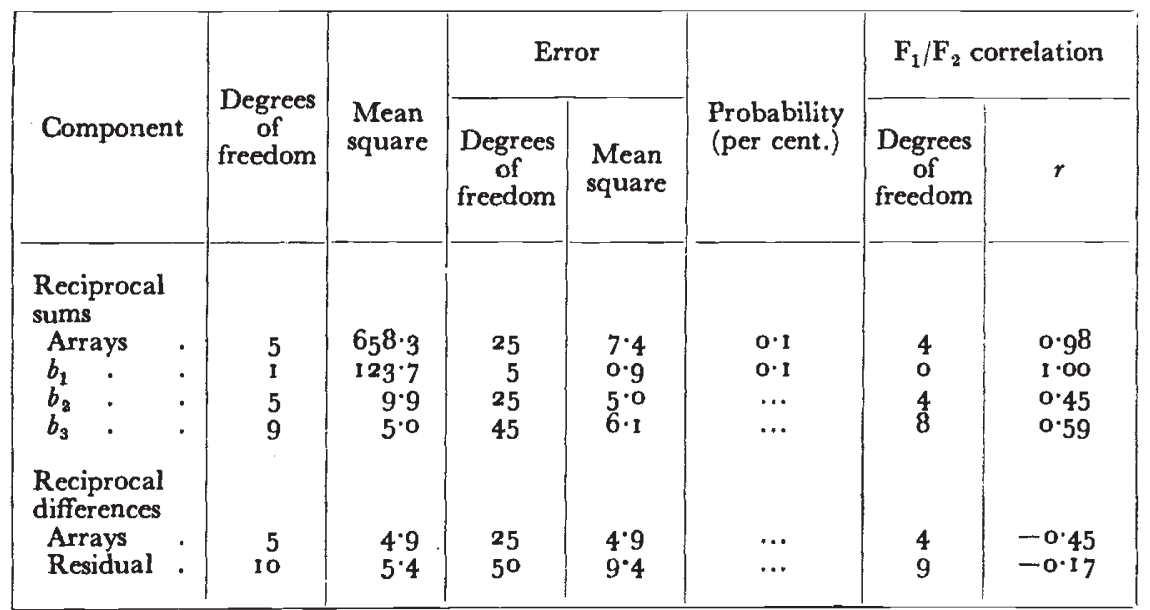

have a suggestively high correlation taken together. The negative correlations among the reciprocals have a high probability of being due to error.

The average dominance deviation in the $\mathrm{F}_{2}$ should be half that in $F_{1}$, if the two generations were grown under comparable conditions, and the displacement of the $\mathrm{F}_{2}$ regression line, $\mathrm{Wr} / \mathrm{V} r$, from the line of unit slope through the origin should be approximately twice that of the $F_{1}$ regression line. Although the two generations here were grown in separate years their mean plant weights were almost the same, 79 and 75 grams respectively for the $F_{1}$ and $F_{2}$, and a comparison of $\mathrm{Wr} / \mathrm{V} r$ regression of $\mathrm{F}_{1}$ and $\mathrm{F}_{2}$, for the original data (figs. $\mathrm{I}$ and 5 ) and the transformed data (figs. 2 and 6) shows that the expected displacement is obtained. As regards the genotrophs themselves, the $F_{1}$ had an average dominance value of 0.68 ; in the $F_{2}$ this drops to $0 \cdot 22$, a reduction which, although somewhat greater than expectation, suggests that in this respect also the genotrophs are behaving in the same way as the genotypes.

Analyses of side shoot weights and centre shoot weights gave $\mathrm{Wr} / \mathrm{Vr}$ 
regression slopes of 0.99 and 0.97 respectively, the positions of the points approximating to those for plant weights in fig. 5. There is therefore no evidence of interaction in the $F_{2}$.

The conclusions to be drawn from the $F_{2}$ family means, which are based upon a larger number of plants growing in more uniform conditions than were the $F_{1}$ means, are essentially the same as those from the $F_{1}$. The genotrophs show a somewhat greater similarity to each other than to the genotypes in their behaviour on crossing but do not appear to be fundamentally different from them.

\section{ANALYSIS OF $F_{2}$ FAMILY VARIANCES}

The variances of the $F_{2}$ families summed over the six replicates are given in table 4. There are large differences between the variances of the parental families, and their standard deviations show almost complete correlation $(r=0.94)$ with the means. On the other hand there is a marked difference in the variances of the reciprocal crosses between the two genotrophs, which are not correlated with their means, 357 and $67 \mathrm{I}$ for $\mathrm{L} \times \mathrm{S}$ and $\mathrm{S} \times \mathrm{L}$ respectively, for these have an identical mean value of 59. This difference is in the same direction as was obtained in a number of crosses between these two genotrophs (Durrant, $1962 b$ ), and there can be little doubt that it is real. In this experiment the $\mathrm{L} \times \mathrm{S}$ cross does not show the increase in variation over the parental variation found in those other experiments, probably because of environmental differences between the experiments.

After a log. transformation of the original data the correlation between the parental means and standard deviations disappears $(r=-0 \cdot 13)$ and further analysis of the family variances was made on the transformed data. As observed, there is a better $F_{1} / F_{2}$ correlation when the transformed data are used. The family variances after transformation, summed over the six replicates, are given in table 4 . The parental variances can be grouped into the two flax genotypes which have the lowest variances, the two linseed genotypes which have higher values, and the two genotrophs which have the highest values. Studies on the between plant, within genotroph variation, as for example those previously reported (Durrant, 1962), gave no evidence that any of it is inherited, and it would appear therefore that, allowing for differences in weight between the genos, the genotrophs are developmentally less stable than the flax or linseed genotypes.

Overall, the $F_{2}$ families have an average value of ${ }_{155}$ compared with an average value for the parental families of 1 i 8 , an increase which is presumably at least in part due to segregation and recombination. The difference between the $\mathrm{L} \times \mathrm{S}$ and $\mathrm{S} \times \mathrm{L}$ variances remains after transformation, the $\mathrm{S} \times \mathrm{L}$ cross having the highest variation of all the $\mathrm{F}_{2}$ families with the exception of $\mathrm{M} \times \mathrm{D}$, one of the flax times linseed crosses, which exceeds it only by a small amount.

The diallel table of family variances can be analysed as though it were a diallel table of family means provided it is suitably interpreted. 
An analysis of variance of the variances is given in table 6 , where only one component, $b_{1}$, shows significance when tested against its error, and is of course due to the overall increase of $F_{2}$ variation over the

TABLE 6

Analysis of variance of $F_{2}$ family variances of log. plant weights. Mean squares $\times 10^{8}$.

\begin{tabular}{|c|c|c|c|c|c|c|}
\hline \multirow{2}{*}{\multicolumn{2}{|c|}{ Component }} & \multirow{2}{*}{$\begin{array}{l}\text { Degrees of } \\
\text { freedom }\end{array}$} & \multirow{2}{*}{$\begin{array}{l}\text { Mean } \\
\text { square }\end{array}$} & \multicolumn{2}{|c|}{ Error } & \multirow{2}{*}{$\begin{array}{r}\text { Probability } \\
\text { (per cent.) }\end{array}$} \\
\hline & & & & $\begin{array}{l}\text { Degrees of } \\
\text { freedom }\end{array}$ & $\begin{array}{l}\text { Mean } \\
\text { square }\end{array}$ & \\
\hline \multicolumn{7}{|c|}{ Reciprocal sums } \\
\hline Arrays & & 5 & $412 \cdot 5$ & 25 & $435^{\circ} 0$ & \\
\hline$b_{1}$. & & I & I $69 \cdot 8$ & 5 & $160 \cdot 6$ & $<5$ \\
\hline$b_{2}$ & . & 5 & $101 \cdot 3$ & 25 & $184 \cdot 4$ & $\cdots$ \\
\hline$b_{3}$ & & 9 & $3^{11} \cdot 3$ & 45 & $350^{\circ} \cdot 1$ & $\cdots$ \\
\hline \multicolumn{7}{|c|}{ Reciprocal differences } \\
\hline Arrays & $\cdot \quad \cdot$ & 5 & $32 \cdot 2$ & 25 & $208 \cdot 2$ & $\cdots$ \\
\hline Residual & & Io & $306 \cdot 8$ & $5^{\circ}$ & $366 \cdot 2$ & $\cdots$ \\
\hline
\end{tabular}

parental variation noted above. The array covariance/variance graph calculated from the summed reciprocals, is shown in fig. 7 , where the points tend to fall on a straight line of unit slope apart

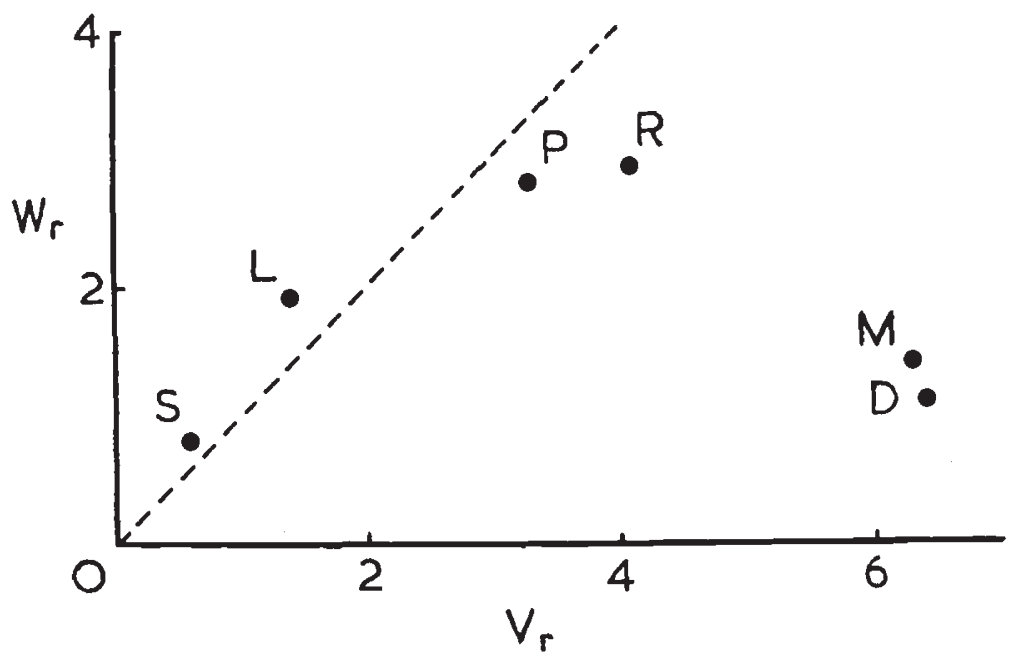

FIG. 7.-Array covariance/variance $\left(\times{ }_{10} 0^{4}\right)$ regression of $F_{2}$ family variances of log. plant weights.

from those of 2 and 4 , whose deviations result from the large $F_{2}$ variation arising from the cross between these two genotypes, also noted above. The genotrophs have the lowest $(\mathrm{Wr}+\mathrm{Vr})$ values, implying that they have a dominating effect upon the genotypes in determining the amount of variation in the crosses. 
The analysis of variance (table 6) shows that there are significantly low values for array reciprocal differences when they are tested (table 7) against their error $(P<0.05)$, against the residual reciprocal differences $(P=0$ or nearly), and against the error residual reciprocal differences $(\mathrm{P}<0 \cdot 0 \mathrm{I})$, all of which imply the presence of negative correlations. They suggest that reciprocal differences are balanced out along the male and female arrays, the pattern changing in the different environments of the replicates. The change in pattern from replicate to replicate alters to a lesser extent the array reciprocal differences between replicates, resulting in a relatively high error array reciprocal differences compared with the array recpriocal

TABLE 7

Variance ratios given by reciprocal differences components when tested against the array reciprocal differences. Extracted from table 6. Mean squares $\times 10^{6}$

\begin{tabular}{|c|c|c|c|c|}
\hline Component & $\begin{array}{l}\text { Degrees } \\
\text { of freedom }\end{array}$ & Mean square & $\begin{array}{l}\text { Variance } \\
\text { ratios }\end{array}$ & $\begin{array}{l}\text { Probability } \\
\text { (per cent.) }\end{array}$ \\
\hline $\begin{array}{l}\text { Reciprocal differences } \\
\text { Residual : } \\
\text { Arrays error } \\
\text { Residual error : } \\
\text { Arrays : }\end{array}$ & $\begin{array}{r}10 \\
25 \\
50 \\
5\end{array}$ & $\begin{array}{r}306 \cdot 8 \\
208 \cdot 2 \\
366 \cdot 2 \\
32 \cdot 2\end{array}$ & $\begin{array}{c}9 \cdot 53 \\
6 \cdot 47 \\
11 \cdot 37 \\
\ldots\end{array}$ & $\begin{array}{c}\text { I (nearly) } \\
5 \\
1 \\
\ldots\end{array}$ \\
\hline
\end{tabular}

differences, although this variance ratio is not so high as the others: in fact the error array reciprocal difference is nearly significantly lower (at the 5 per cent. level) than the error residual reciprocal differences.

One would require confirmation from other experiments before accepting these differences as being real, and the significance of the low array reciprocal differences is rendered more likely than is indicated by the I per cent. probability by the number of components which are being tested in the overall analysis. Nevertheless, there is some consistency in the data, for table 8 shows that the residual reciprocal differences are greater than the array reciprocal differences in the five out of the six replicates.

One approach to the examination of the negative correlations is to remove the arrays one at a time, and in pairs, to determine which are mainly responsible by noting the alteration in the variance ratio for residual reciprocal differences/array reciprocals differences which, in the full diallel table, is 9.53 . Those arrays which decrease this ratio when they are removed are those which are more involved, and those which increase it, less involved. The ratios obtained have been arranged in diallel form in table 9 where the "parents" are those removed singly and the "crosses", which are entered twice to complete the table, those removed in pairs. The marginal totals can be arranged in three distinct groups. The two flax genotypes are most involved, 
the two genotrophs are somewhat less, and the two linseed genotypes least, involved. This is a rough assessment, but it is revealing in that the groupings are related to the mode of origin of the genos, by the selection for flax genotypes, the selection for linseed genotypes, and by environmental induction.

TABLE 8

Variance ratios given by array reciprocal differences and residual reciprocal differences for the six replicates. Mean squares $\times 10^{8}$

\begin{tabular}{|c|c|c|c|c|}
\hline \multirow{2}{*}{ Replicate } & \multicolumn{2}{|c|}{$\begin{array}{l}\text { Reciprocal differences } \\
\text { Mean squares }\end{array}$} & \multicolumn{2}{|c|}{ Variance ratio } \\
\hline & Arrays (c) & Residual (d) & $\frac{\mathrm{d}}{\mathrm{c}}$ & $\frac{c}{d}$ \\
\hline $\begin{array}{l}1 \\
2 \\
3 \\
4 \\
5 \\
6\end{array}$ & $\begin{array}{r}68 \\
567 \\
75 \\
98 \\
214 \\
50\end{array}$ & $\begin{array}{l}187 \\
342 \\
154 \\
197 \\
931 \\
327\end{array}$ & $\begin{array}{l}2 \cdot 7 \\
\ldots \\
2 \cdot 1 \\
2 \cdot 1 \\
4 \cdot 4 \\
6 \cdot 5\end{array}$ & $\begin{array}{l}\ldots \\
1 \cdot 7 \\
\cdots \\
\cdots \\
\cdots \\
\cdots\end{array}$ \\
\hline
\end{tabular}

TABLE 9

Variance ratios of residual reciprocal differences/array reciprocal differences omitting arrays singly and in pairs (see text). Negative sign indicates $1 / V . R$.

\begin{tabular}{|c|c|c|c|c|c|c|}
\hline & $\mathbf{P}$ & $\mathbf{M}$ & $\mathbf{R}$ & D & $\mathbf{S}$ & $\mathbf{L}$ \\
\hline $\begin{array}{l}\mathbf{P} \\
\mathbf{M} \\
\mathbf{R} \\
\mathrm{D} \\
\mathbf{S} \\
\mathrm{L}\end{array}$ & $\begin{array}{r}2 \cdot 3 \\
1 \cdot 6 \\
3 \cdot 0 \\
7 \cdot 3 \\
2 \cdot 7 \\
-6 \cdot 5\end{array}$ & $\begin{array}{l}1 \cdot 6 \\
2 \cdot 1 \\
1 \cdot 3 \\
2 \cdot 4 \\
1 \cdot 7 \\
1 \cdot 7\end{array}$ & $\begin{array}{r}3 \cdot 0 \\
1 \cdot 3 \\
11 \cdot 5 \\
50 \cdot 0 \\
6 \cdot 6 \\
20 \cdot 4\end{array}$ & $\begin{array}{r}7 \cdot 3 \\
2 \cdot 4 \\
50 \cdot 0 \\
49 \cdot 9 \\
1 \cdot 3 \\
2 \cdot 4\end{array}$ & $\begin{array}{r}2.7 \\
1.7 \\
6.6 \\
1.3 \\
11.6 \\
7.4\end{array}$ & $\begin{array}{r}-6.5 \\
1.7 \\
20.4 \\
2.4 \\
7.5 \\
1.5\end{array}$ \\
\hline \multirow[t]{2}{*}{ Total } & $10 \cdot 4$ & $10 \cdot 8$ & $\underbrace{92 \cdot 8}$ & 113.3 & $\underbrace{31 \cdot 4}$ & $27 \cdot 0$ \\
\hline & \multicolumn{2}{|c|}{ flax genotypes } & \multicolumn{2}{|c|}{$\begin{array}{l}\text { linseed } \\
\text { genotypes }\end{array}$} & \multicolumn{2}{|c|}{ genotrophs } \\
\hline
\end{tabular}

There are a number of ways of analysing reciprocal differences in diallel crosses, taking into account dominance and gene interaction (Durrant, to be published). A particularly useful one is the comparison of the covariance of male and female arrays respectively onto the parental values. Briefly, if the female array covariances are plotted against the male array covariances entered on the abscissa, and if there are no reciprocal differences, the points should lie on a straight line of unit slope passing through the origin. If there is consistent maternal inheritance throughout the data then the points will remain on a straight line of unit slope but the line itself will be depressed. 
Similarly, consistent paternal inheritance will raise the line. If nuclear/cytoplasmic interactions occur the points for the parents involved will be thrown off perpendicular to the straight line in the appropriate directions. If an extreme situation should exist such that there is strong, relatively uniform maternal and paternal inheritance in different arrays then the points may be thrown off to such an extent

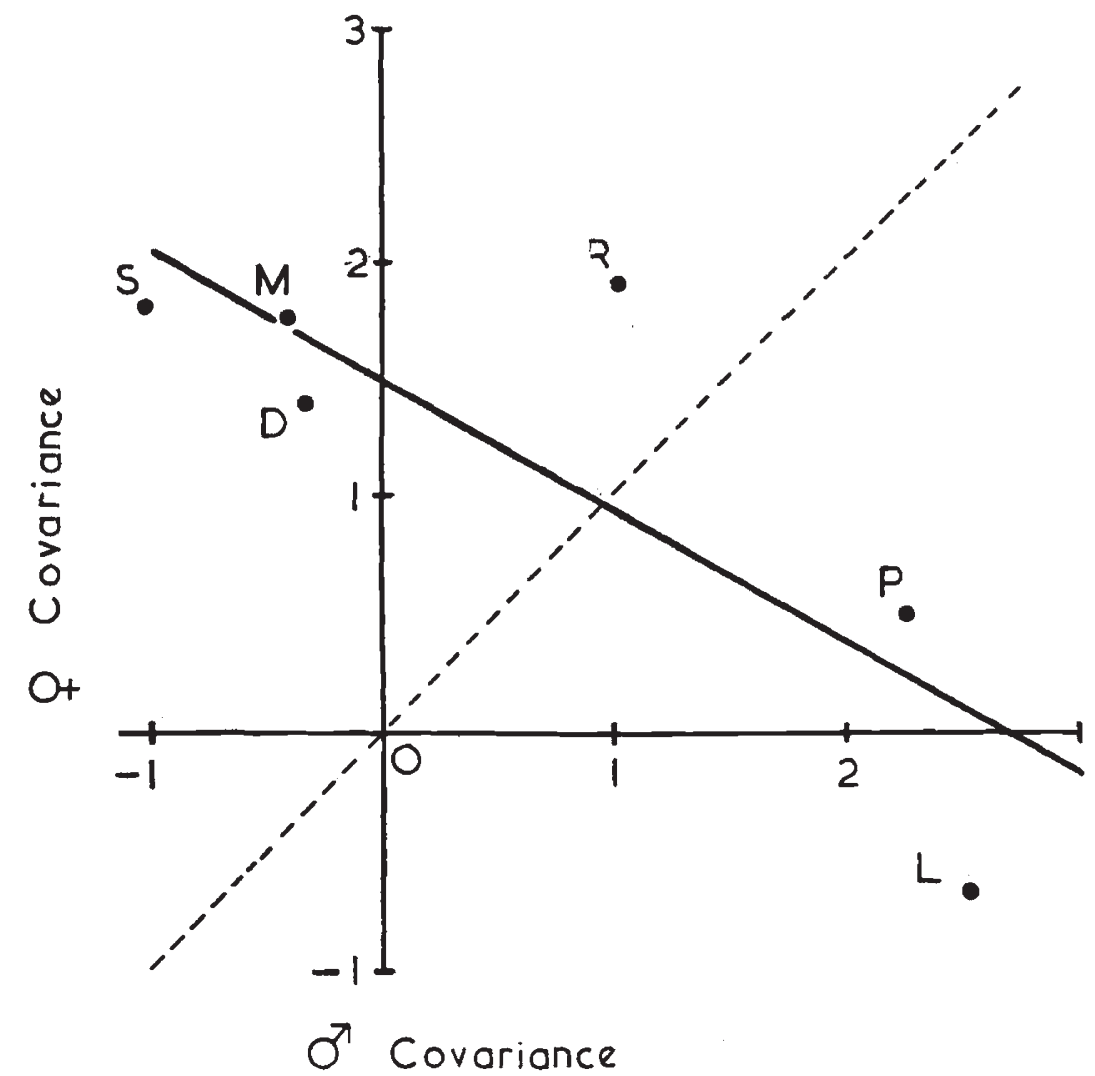

Fig. 8.-Male/female array covariance $\left(\times 10^{4}\right)$ regression of $F_{2}$ family variances of log. plant weights. $b=-0 \cdot 55$.

as to give a line of negative slope, depending upon the relative magnitudes of the maternal and paternal inheritance and the magnitude and pattern of dominance and gene interaction.

The female and male covariances have been plotted in fig. 8. A line of negative slope is obtained $(b=-0.55)$ which is significant $(\mathrm{P}<0.05)$. The correlation coefficient is -0.82 , and the two genotrophs take up extreme positions. $\mathrm{L}$ is depressed and $\mathrm{S}$ raised, the interpretation being that in crosses with $\mathrm{L}$ there is maternal inheritance, and in crosses with $\mathbf{S}$ there is paternal inheritance. Similarly, but of lesser magnitude, in crosses with $\mathrm{P}$ there is maternal inheritance, and in crosses with $M$ there is paternal inheritance. The two linseed varieties, $R$ and $D$, have more central positions. 
In fig. 9(a), (b), (c), pairs of genos have been removed in turn from the diallel table before calculating the covariances. In fig. 9(a) the two genotrophs have been omitted and there is at once a change from a negative to a positive slope $(b=0.75$, and $r=0.74)$. Evidently

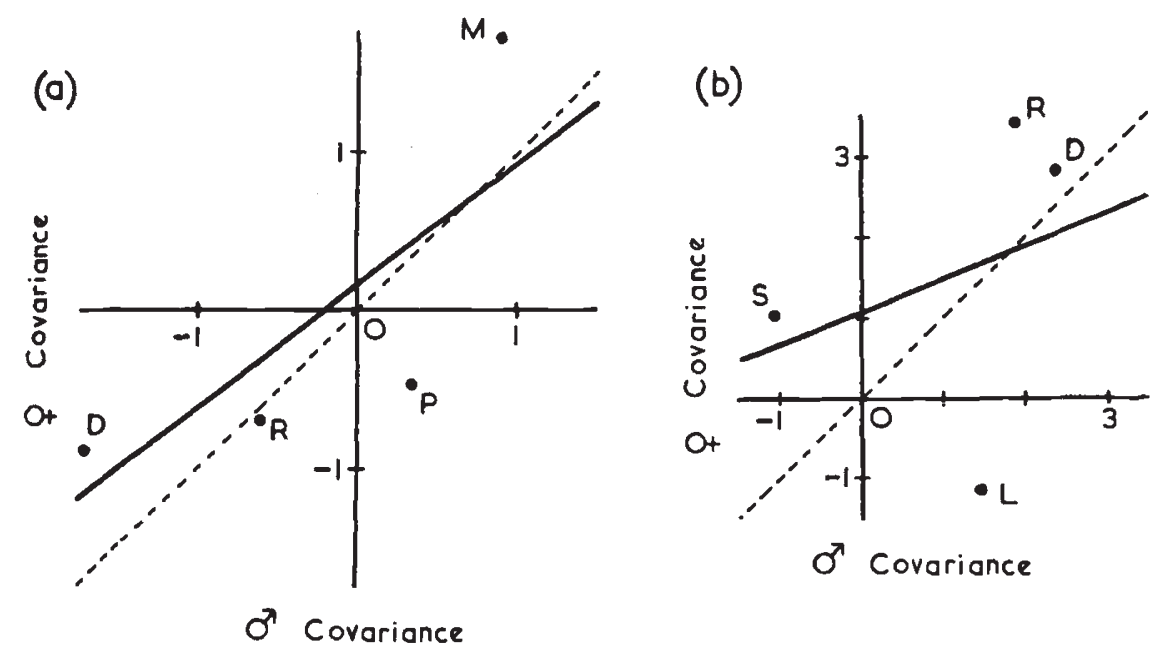

(c)

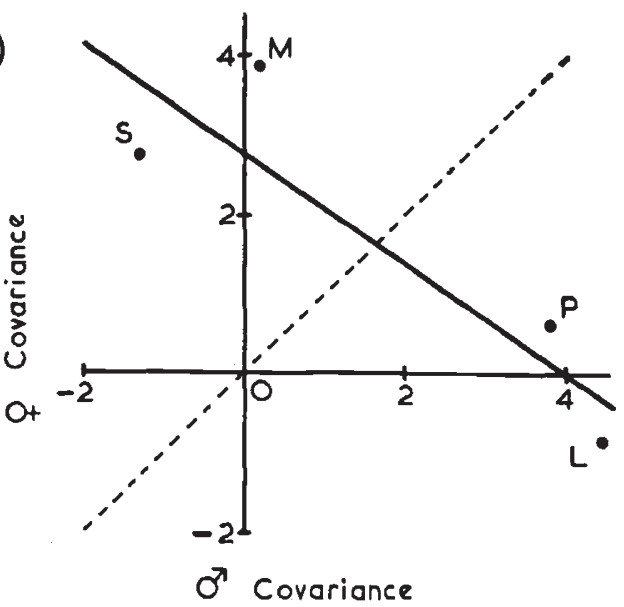

Fig. 9.-Male/female array covariances $\left(\times 10^{4}\right)$ regression of $F_{2}$ family variances of $\log$. plant weights. Scale of (a) has been enlarged. The covariances are greatest in (c) and least in (a).
(a) L and S omitted. $b=0.75$.
(b) P and M omitted. $b=0.45$.
(c) $\mathrm{R}$ and $\mathrm{D}$ omitted. $b=-0.69$.

the presence of the genotrophs is necessary for the pattern of reciprocal differences to appear but it is not, and cannot be, due to the reciprocal crosses $\mathrm{L} \times \mathrm{S}$ and $\mathrm{S} \times \mathrm{L}$ alone, and if the means of these reciprocals are entered in both cells of the full table the regression line is hardly altered.

In fig. 9 (b) the two flax genotypes have been omitted. Here again 
there is a positive slope $(b=0.45$, and $r=0.34)$ but with a difference. The correlation is much lower, for while the two linseed genotypes take up a central position, and are in fact practically on the line of unit slope passing through the origin, the two genotrophs are negatively correlated, supplying additional evidence that the linseed genotypes are not directly involved, but the genotrophs are.

In fig. 9 (c) the two linseed genotypes have been removed and the negative slope returns $(b=-0.69$, and $r=-0.92)$. There is an extremely high negative correlation and the relative positions of the four points have hardly altered from those in fig. 8 containing all six points.

The conclusions are that the presence of the genotrophs is necessary for the pattern of reciprocal differences to occur, neither the linseed genotypes nor the flax genotypes producing this type of relation alone or together, but whereas the linseed genotypes are only indirectly involved the flax genotypes appear to acquire the same characteristics as the genotrophs themselves.

In fig. 8 the negative slope is less than unity $(b=-0.55)$ which means there is a tendency for genos with maternal inheritance to be more recessive on average than genos with paternal inheritance. Further analysis, which will be detailed elsewhere, shows that in crosses with $\mathrm{S}$, the progeny are influenced more by the $\mathrm{S}$ male parent rather than by the male parents of the other genos. In crosses with $\mathrm{L}$, the $\mathrm{L}$ female parent and the female parents of the other genos influence the progeny to about the same extent.

The pattern of reciprocal differences in the $F_{2}$ variances is unrelated to the $\mathrm{F}_{2}$ family means. The reciprocal $\mathrm{F}_{2}$ family means are very similar throughout table 4 , and the male and female covariance graph gives points close to the line of unit slope through the origin. Nor is it related to the $F_{1}$ family means (table $I$ ), although here the reciprocal differences may be somewhat greater, and there is more pronounced maternal inheritance in the male/female covariance graph, with the exception of $\mathrm{S}$ which gives slight paternal inheritance. In the analyses (tables 2 and 5) the array and residual reciprocal differences components are about the same.

The occurrence of fairly consistent male and female inheritance of the $\mathrm{F}_{2}$ family variances is not in itself responsible for the residual reciprocal differences being significantly larger than the array reciprocal differences. There must also be deviations from this pattern along the male and female arrays. The comparatively large error variance for the residual reciprocal differences might be explained, although not entirely convincingly, by antagonism arising in crosses between parents with patrilinear and matrilinear propensities. Even in the $F_{1}$ and $F_{2}$ family means in each case the error residual reciprocal differences component is significantly larger (tables 2 and $5, \mathrm{P}<5$ per cent.) than the array reciprocal differences, although no $F_{1} / F_{2}$ correlation could be found here when plants from the two $F_{1}$ replicates were 
traced among the six $F_{2}$ replicates. Nevertheless sufficient analysis has been given to indicate the probable occurrence of maternal and paternal inheritance in the $F_{2}$ variances, their magnitudes being related to the origins of the genos themselves.

\section{DISCUSSION}

In previous studies the two genotrophs behaved as though they were distinct genetic types in inheritance, crosses and grafts when their mean values alone were examined. They displayed unusual properties only in the variation arising in their crosses, in the greater variation exhibited by the $F_{1}$ and $F_{2}$ of the $S \times L$ cross compared with the $\mathrm{L} \times \mathrm{S}$ cross, and in the inheritance of the variation released in the $F_{1}$. In the present experiment the same type of result is obtained. In the analysis of the family means of the $F_{1}$ and $F_{2}$, which give almost identical results apart from the reduction in dominance, the genotrophs behave in no way different from the genotypes and fit remarkably well into the overall pattern. In the $F_{2}$ family variances, on the other hand, not only does the large variation in the $\mathrm{S} \times \mathrm{L}$ cross appear but there are also pronounced reciprocal differences elsewhere in the data and the genos appear to have different male and female propensities for the inheritance of variation.

The variation within $F_{2}$ families may be of three sorts, (i) environmental; (ii) genetic, i.e. due to segregation and recombination; (iii) epitrophic, e.g. the heritable variation arising in the $F_{1}$ of crosses between the genotrophs (Durrant, $1962 b$ ). The differences between families in their within family variation may therefore be determined by the different genetic constitution of the parents (gene interaction, additive and dominance effects, linkage), by their stability (genotype/ environment interaction) which is also a function of the genotype, and by the possession of epitrophic properties which may not be a characteristic solely of the genotrophs. A strong correlation between parent and offspring variation suggests that, in the absence of any known genetic differences between plants within genos, stability is important. The progeny of plants with high variability, for example, may also have high variability, and the $F_{2}$ variation could be viewed as a character, and analysed as a character, which is genetically determined.

Four interpretations of the differences in variation between reciprocal crosses need to be considered. (i) They may be due to the influence of the maternal and paternal environments on the expression of the products of recombination and segregation. (ii) Genetic factors determining stability may be more effective when transmitted through the male, or the female, gametes depending on the cross. (iii) Positive correlation with the maternal parents may be due to maternal, quite apart from cytoplasmic, effects, where by maternal effects, as distinct from maternal inheritance, is meant the initial advantage or disadvantage conferred on the developing plant by differences in seed 
weight, nutrient content, or condition of ripening. Positive correlation with the paternal parents may be due to the varying quality and quantity of pollen producing variable seed setting resulting in maternal effects. While it is conceivable that direct maternal effects occur, taking all observations into account there is little to be said for the indirect effect of the pollen. Yet positive correlations with the male parents are interesting because they imply that differences between single cells can have a profound influence on all subsequent growth, that is, they are differentiated or capable of inducing differentiation, although the initial differences themselves may be only hormonal or nutritional. They also imply that maternal positive correlations may not be solely due to maternal effects. (iv) The reciprocal differences may be due to the differential transmission of actual heritable changes brought about by changes in metabolic activity associated with the plant to plant variation. That is to say, the variation between plants might be viewed as differences in biochemical activity which are potentially heritable, or capable of producing changes that are heritable, and may be metabolic, developmental or akin to differentiation.

The last hypothesis is not altogether unreasonable. The differential transmission involves the genotrophs principally, and there is good evidence from other experiments of a pronounced reciprocal difference in the $F_{1}$ variation and in their $F_{2}$, and that some of the $F_{1}$ variation is inherited. In crosses with other varieties similar processes may occur, the nuclear variation, supposing it to be nuclear variation, interacting with the male and female gametic environments and with the new intracellular environment of the hybrid. The propensity for its transmission in these other crosses seems to be greatest in the $\mathrm{L}$ female parent and $\mathrm{S}$ male parent. From a general point of view, and without trying to interpret all differential transmission in terms of the cytoplasm, in some cases the nucleus of the male parent may be potentially more efficient in transmitting changes than the nucleus of the female parent which is in association with its own cytoplasm. A number of cases have arisen in other crosses not reported here where the male parents appear to influence the growth of their progeny, at least at the early stages, more than the female parents. The rogue character in peas is transmitted more efficiently by the male parent.

A further question is how far the other genotypes used in the diallel cross participate in bringing about the reciprocal differences. Apart from the intracellular environment they help provide they may be activated by the genotrophs in crosses with them to exhibit similar characteristics to them, which, if we were to seek a comparison elsewhere, may have its counterpart in paramutation, the initial genotrophic change, i.e., the induction of the genotrophs, having its counterpart in differentiation. Yet although such phenomena as differentiation, paramutation and genotrophism invite comparison it would be unwise to suppose that they are necessarily determined by the same mechanisms. There are in addition those other, generally 
regarded more superficial, changes and patterns in organisms such as those resulting in reciprocal differences in some crosses, particularly those in paternal directions, or those processes responsible for a great part of the variation in inbred lines of Drosophila. Recently, for example, Lawrence ( I $^{6} 3$ ) has reported significant reciprocal differences in recombination frequencies in a diallel cross between strains of Drosophila melanogaster, where some were in paternal directions, and numerous other instances could be cited. They are worthy of further examination; at best they would yield interesting and relevant information; at worst more would be known about them.

Measurement of the $F_{1}$ family variances of the diallel cross would have helped interpretation, but it would need to be accompanied by progeny testing of individual parent and $F_{1}$ plants to be of most value, which would have made the present experiment unwieldly. The $F_{1}$ variation was not recorded because, apart from the smaller number of plants, the large soil heterogeneity would have caused erratic variance estimates and maternal effects in the $F_{1}$ associated with the crossing process itself can be greatly exaggerated under poor growing conditions. Further crossing experiments will deal with specific crosses more intensively.

In the $F_{1}$, the reciprocal crosses between the large and small genotrophs had practically the same weights, 57 and 54 for $\mathrm{L} \times \mathrm{S}$ and $\mathrm{S} \times \mathrm{L}$ respectively, so that the average dominance values, i.e. potence ratios, were also close, 0.76 and 0.59 . In the $\mathrm{F}_{2}$, the reciprocal crosses were identical in weight and the average dominance value had dropped to 0.22 . Average dominance is expected to drop by a half from the $F_{1}$ to the $F_{2}$ due to segregation so that these results conform fairly well and suggest that factors responsible for the difference between the large and small genotrophs reside on the chromosomes. Nevertheless this is suspect because the variation is different in the reciprocal crosses, the $\mathrm{S} \times \mathrm{L} \mathrm{F} \mathrm{F}_{2}$ variance being twice that of $\mathrm{L} \times \mathrm{S}$, and the drop in average dominance in the $\mathrm{L} \times \mathrm{S}$ cross should be less than in the $\mathrm{S} \times \mathrm{L}$ cross, whereas in fact the difference in magnitude of the drop is, if anything, in the other direction. There is evidence from the $F_{1} / F_{2}$ correlation elsewhere (Durrant, $1962 b$ ) that the $F_{2}$ variation is not due entirely to classical segregation, and therefore neither segregation nor the production of large and small types (epitrophs) in the crosses would appear to be responsible for the change in average dominance from the $\mathrm{F}_{1}$ to the $\mathrm{F}_{2}$.

These relations are summarised in table 10, where there are also included the results of other experiments, and these give the same type of result. In these other experiments there is no reduction in average dominance whatsoever in the $\mathrm{S} \times \mathrm{L}$ cross where it would be expected to be greater since here also this cross has twice the variation of the $\mathrm{L} \times \mathrm{S}$. The variation arising in the $\mathrm{F}_{1}$ and $\mathrm{F}_{2}$ of the $\mathrm{S} \times \mathrm{L}$ is associated with no decrease in dominance, whereas in the $\mathrm{L} \times \mathrm{S}$ cross where the variation is less, dominance drops virtually to zero in the $F_{2}$. 
Although these observations refer to the properties of two genotrophs these properties need not necessarily be exclusively those of genotrophs, and in any case genotroph and genotype are best looked on as relative terms. It may be that they are the more easily observed with individuals unadulterated by classical gene differences, or the genes themselves are dictatorial over the processes responsible. Quantitative variation may be in part due to processes which are

TABLE 10

Dominance in the $F_{1}$ and $F_{2}$ of reciprocal crosses between the genotrophs, and $F_{2}$ variation

\begin{tabular}{|c|c|c|c|c|c|}
\hline & & \multicolumn{2}{|c|}{ From diallel } & \multicolumn{2}{|c|}{$\begin{array}{l}\text { From other experiments } \\
\text { (Durrant, } 1962 b)\end{array}$} \\
\hline & & $\mathrm{L} \times \mathrm{S}$ & $\mathbf{S} \times \mathbf{L}$ & $\mathbf{L} \times \mathbf{S}$ & $\mathbf{S} \times \mathbf{L}$ \\
\hline $\begin{array}{l}\mathbf{F}_{1} \text { dominance } \\
\mathbf{F}_{2} \text { dominance }\end{array}$ & $: \quad:$ & $\begin{array}{l}0 \cdot 76 \\
0 \cdot 22\end{array}$ & $\begin{array}{l}0.59 \\
0.22\end{array}$ & $\begin{array}{l}0.3^{8} \\
0.08\end{array}$ & $\begin{array}{l}0.32 \\
0.32\end{array}$ \\
\hline$F_{1}-F_{2}$ dominance & . & 0.54 & 0.37 & 0.30 & o \\
\hline$F_{2}$ variance & . & 357 & 671 & 306 & 705 \\
\hline
\end{tabular}

similar to those occurring in the genotroph crosses, and heterosis and inbreeding depression may be due in part to the formation, and breakdown, of interacting and contrasting biochemical processes rather than to the mechanical bringing together and separation of different chromosomal genes which interact and have dominance relations.

\section{SUMMARY}

A diallel cross was made between the large and small genotrophs of Stormont Cirrus, two other flax varieties and two linseed varieties. The two genotrophs had previously been induced by temperature and fertiliser treatments and were stable in inheritance. Both in the $F_{1}$ and $F_{2}$ the large and small genotrophs conformed to the general pattern of dominance exhibited by the other varieties in family mean plant weight, and behaved as though they were distinct genetic types. There were no pronounced gene interactions nor reciprocal differences.

The $F_{2}$ family variances were, on the other hand, exceptional in showing large reciprocal differences for individual crosses, although the reciprocal differences between male and female array totals were small. $\quad F_{2}$ family variances of crosses with the large genotroph were roughly the same as the maternal variances and those of crosses with the small genotroph were similar to the paternal variances. The two other flax varieties had somewhat similar characteristics in crosses with the genotrophs. Although individual reciprocal differences 
vary between replicates it seems that variation between parent plants, or between gametes of individual parent plants, of a non-classical genetic nature may be potentially heritable, the inheritance being dependent upon the effectiveness of the transmission through the male or female gametes, and the new intracellular environment of the hybrid.

$\mathrm{F}_{2}$ variation was greater in the $\mathrm{S} \times \mathrm{L}$ cross than in the $\mathrm{L} \times \mathrm{S}$ cross yet this difference was not reflected in the drop in dominance from the $F_{1}$ to the $F_{2}$ in the reciprocal crosses, suggesting that the change in dominance was not due to segregation but to other processes. These processes may also play a part in heterosis and inbreeding depression in other plants and animals wherein they may be less readily observed due to the presence of classical gene differences.

The results agree with those of previous experiments in that the genotrophs behave in general as distinct genetic types as far as their family means are concerned but display unusual properties in their variances.

\section{REFERENCES}

DURrant, A. 1962a. The environmental induction of heritable change in Linum. Heredity, $17,27-61$.

DURRANT, A. $1962 b$. Induction, reversion and epitrophism of flax genotrophs. Nature, 196, 1302-1304.

HAYMAN, B. 1. 1954. The analysis of variance of diallel tables. Biometrics, Io, 235-244.

JINKs, J. L. I954. The analysis of continuous variation in a diallel cross of Nicotiana rustica varieties. Genetics, 39, 767-788.

LAWRENCE, M. J. 1963. The control of crossing-over in the X-chromosome of Drosophila melanogaster. Heredity, 18, 27-46.

WIGAN, L. G. 1944. Balance and potence in natural populations. F. Genetics, 46, 150-160. 